\title{
EL IMPACTO DEL CONFINAMIENTO EN LA SUBJETIVIDAD DE LA ÉPOCA
}

\section{Harraca, María Florencia}

\section{Resumen:}

Nuestro trabajo tiene por objetivo indagar acerca de los efectos del confinamiento generado por la pandemia Covid-19 en la subjetividad contemporánea e interrogar sobre los desafíos que se imponen hoy a la clínica psicoanalítica. Partimos de la afirmación de Lacan (1953/1979): "Mejor pues que renuncie quien no pueda unir a su horizonte, la subjetividad de su época” (p. 138). Nos proponemos investigar cómo se podría sostener esta máxima, tomando como referencia un horizonte conformado por la consideración de la subjetividad de nuestra época. La pandemia nos ha confinado: eso implica un proceso de ruptura en cierto orden significante de la vida de los sujetos. Sin embargo, gracias a la hipervirtualidad en que estamos inmersos, en parte como consecuencia del confinamiento, se puede caer en la ilusión de que nada se detuvo. Nos hemos acostumbrado a las reuniones virtuales de todo tipo y hasta sesiones de psicoanálisis online. Lo cierto es que ya nada será igual. Nos preguntamos: ¿Puede el psicoanálisis, en tiempos de pandemia y confinamiento, no retroceder ante la angustia que causan los fenómenos sintomáticos de este tiempo y brindar una clínica adecuada? ¿Puede estar a la altura de los desafíos que este tiempo nos plantea?

Palabras clave: Pandemia - Confinamiento - Hipervirtualidad - Clínica Psicoanalítica

\section{Abstract:}

Our work aims to inquire about the effects of the confinement generated by the Covid-19 pandemic on contemporary subjectivity and to question the challenges that are imposed today on the psychoanalytic clinic. We start from the affirmation of Lacan (1953/1979): "Better than that those who cannot unite to their horizon the subjectivity of their time should resign." (p. 138). We intend to investigate how this maxim could be sustained, taking as a reference a horizon shaped by the consideration of the subjectivity of our time. The pandemic has confined us: that implies a process of rupture in a certain significant order of the life of the subjects. However, thanks to the hyper-virtuality in which we are immersed, partly as a consequence of the confinement, one can fall into the illusion that nothing has stopped. We have become accustomed to virtual meetings of all kinds and 
even online psychoanalysis sessions. The truth is that nothing will be the same. We ask ourselves: Can psychoanalysis, in times of pandemic and confinement, not shrink from the anguish caused by the symptomatic phenomena of this time and provide an adequate clinic? Can it rise to the challenges that this time poses for us?

Keywords: Pandemic - Confinement - Hypervirtuality - Psychoanalytic Clinic

\section{INTRODUCCIÓN}

Algunas consideraciones en torno al confinamiento.

El estado de confinamiento, también conocido como aislamiento social preventivo y obligatorio, es una medida epidemiológica dictaminada por la OMS (2020) que ha sido adoptada por la mayoría de los países en todo el mundo.

Vivir en estado de confinamiento nos confronta con determinados límites a nuestras condiciones habituales de existencia y con un proceso de ruptura en cierto orden significante de la vida. Las cosas más simples y comunes, ahora se encuentran en estado de interrupción.

\section{LOS LÍMITES DEL CONFINAMIENTO}

Uno de los aspectos más salientes del confinamiento es lo que llamamos la suspensión de la vida entre cuerpos. Nuestra vida habitual está hecha de dispositivos presenciales que implican la presencia de los otros, mejor dicho, la presencia del cuerpo del otro. La facultad, actividades deportivas, el consultorio, la escuela, las reuniones afectivas, asistir al trabajo, son todos espacios que nos recuerdan que la vida transcurre y sucede entre cuerpos. A partir de la pandemia y de las medidas tomadas al respecto, esto ha sufrido serias modificaciones.

Nuestra vida social se ha limitado, nuestro trabajo se transformó en home office, el contacto social, la cercanía y las demostraciones físicas de afecto, tocar el cuerpo del otro, tuvieron que ponerse en pausa. Como nunca antes, el otro se ha convertido en una fuente de amenaza, en un ser peligroso al que hay que mantener lo más a distancia posible. Del mismo modo, el virus en sí mismo es una fuente de peligro, que a pesar de ser invisible, la ciencia se ha esforzado por asir y domeñar, al menos en la toma de imágenes digitales, generando en algunos sujetos respuestas subjetivas que pueden ir desde la negación hasta la máxima obsesión por la limpieza. 
Del mismo modo se ha observado una fuerte resistencia de muchos sujetos a quedarse en casa, los llamados grupos anti-cuarentena, que en algunos casos de extrema necesidad, parece justificado continuar con sus actividades laborales para el sostén económico. En otros casos, la rebeldía, la negación, el no tolerar estar encerrado y querer seguir socializando, ha llevado a muchos ciudadanos a hacer como si nada pasara.

Quedate en casa no es solo quedarse en casa. Hacer home office, no es solo trabajar desde la casa, ni asistir a la escuela o a la universidad desde la casa es únicamente hacer la escuela desde casa, sino que implica que desde el interior de nuestras casas se intenta hacer un montaje escénico que entendemos tiene la ilusión de restituir ese mundo de afuera en el que ya no podemos circular ni habitar libremente. Es decir, con el confinamiento se intenta instituir en el interior de nuestros hogares, todo ese mundo exterior que hoy está perdido.

En este sentido, el psicoanálisis como práctica clínica no ha quedado exento de la medida de confinamiento. Si bien el análisis on-line no es algo que resulte novedoso a esta altura, debemos admitir que, en nuestro caso particular, ha implicado romper con serias resistencias de quienes no lo teníamos incorporado aún. Por lo tanto, y trabajando desde la máxima de Lacan de poder unir nuestro horizonte de trabajo a la subjetividad de le época, hemos escuchado en nuestra labor clínica en tiempos de pandemia, de las más variadas reacciones ante una clínica, que esta vez, transcurrió sin el cuerpo.

Algunos sujetos, sobre todo los adolescentes en análisis, eligieron a las videollamadas como medio para sostener su tratamiento. Aquí se destaca en el relato de los pacientes una sobrevaloración a la imagen, sobre todo, el sostén que les da ver la imagen del analista viéndolos. Otros sujetos no necesitan de la imagen, sobre todo aquellos que venían haciendo su análisis en diván, para los cuales la conversación telefónica tradicional es suficiente para poner en juego el dispositivo analítico. Aquí la voz transforma su espesor, el objeto voz más que nunca se convierte en un objeto privilegiado del acto analítico. En otros casos, hemos encontrado con la negativa de varios analizantes a trabajar fuera del encuadre del consultorio. Cada uno con sus razones.

En cualquier caso, el cuerpo del analista y del analizante se encuentra sustraído de la escena analítica cobrando presencia y consistencia a partir de la tecnología. Se pondrán en juego nuevas escenas y la virtualidad tendrá un papel que a continuación nos proponemos indagar.

Como consecuencia de este prominente aspecto del confinamiento que hemos llamado la suspensión de la vida entre cuerpos, surge otro gran aspecto, no menos problemático, 
que es lo que denominamos la hipervirtualidad. La pandemia nos ha confinado: eso implica un proceso de ruptura de cierto orden significante de nuestra vida. Sin embargo, gracias a la hipervirtualidad en que estamos inmersos, en parte como consecuencia del confinamiento, se puede caer en la ilusión de que nada se detuvo.

Entendemos por hipervirtualidad un fenómeno propio de la época que exacerba el uso de la virtualidad en nuestra vida cotidiana, en un contexto de posmodernidad que invita más que a la reflexión, a la impulsión, al goce y al consumo. Consumo de todo tipo de objetos sumado a los avances tecnológicos en donde nada puede esperar bajo el autoritarismo de la instantaneidad. Vivir en situación de confinamiento no le sienta bien al sujeto posmoderno que vive esclavo del imperativo de la época, "anda, goza, consume, compra, compra felicidad, no te detengas, no pares, entrena, sé productivo, sonríe, pero sobre todo, ¡sonríe para la foto que saldrá en las redes sociales!”. Vivimos en un régimen que empuja a un exceso de goce, donde muchas veces el sujeto, en el intento de no encontrarse con su malestar y sus enigmas, queda en un lugar de consumidorconsumido.

Es por ello que en este trabajo proponemos una lectura crítica, con espíritu de interrogación y reflexión acerca de nuestra práctica clínica y de lo que ocurre con el psicoanálisis en este contexto. Los rasgos de la época actual dejan improntas en la subjetividad y en los lazos sociales. Frente a la hipervirtualidad que nos atraviesa, nos preguntamos ¿Qué pasa con cierto imperativo de inmediatez que atraviesa a diferentes discursos? ¿Puede el psicoanálisis, en tiempos de pandemia y confinamiento, no retroceder ante la angustia que causan los fenómenos sintomáticos de este tiempo y brindar una clínica adecuada? ¿Puede estar a la altura de los desafíos que este tiempo nos plantea?

\section{EL LUGAR DEL ANALISTA}

Ante estas preguntas, creemos que el lugar del analista es continuar con su apuesta a la construcción de un espacio abierto a la singularidad y a la verdad de cada caso, que posibilite la subjetivación, a partir de un tiempo no inmediato, no cronológico sino un tiempo lógico propio del sujeto del inconsciente; al contrario del discurso de la ciencia y la religión que sostienen una verdad para todos e imponen formas homogéneas de subjetivación.

El avance de la ciencia y su proliferación de diferentes objetos en el mercado, promueve la ilusión de completud, e intenta taponar la falta, atentando de este modo contra el 
deseo. Estos objetos denominados "gadgets", representan la homogenización de los modos de gozar. Bajo esta línea se sostiene lo que Lacan (1969-70/1992) nombró como el discurso capitalista. Se trata entonces de la promoción de goce, con ausencia de una ley que haga límite. La tecnología muchas veces cumple el papel de un fármaco, y más aún en contexto de pandemia y confinamiento. Nos entretiene, nos evade del malestar y la angustia. Genera la sensación de que nuestra vida pudo seguir adelante del mismo modo solo que en modo on line, o modo home office.

Lo cierto es que una de las razones que más aqueja a los sujetos que se encuentran haciendo home office o su vida on line es el plus de trabajo que ahora tienen, que antes no tenían, donde la jornada laboral se convierte prácticamente en una jornada 24 horas sin corte, sin castración, jornada completa. Docentes que a toda hora reciben tareas de sus estudiantes, estudiantes que se quejan de hacer tareas a toda hora; empleados que se encuentran en un sinfín de ida y vuelta de mails, reuniones laborales por zoom que surgen de un momento a otro.

En consonancia con lo que sucede con nuestra cultura actual, todos estos intercambios virtuales se destacan por su velocidad, en gran parte porque la comunicación es realizada en tiempo real. Esto tiene un punto sumamente problemático, a nuestro entender, ya que se suprime el tiempo de espera, a favor de acelerar el intercambio de caracteres. Muchos sujetos se angustian frente a estos efectos demandantes y fagocitantes de la vida virtual. Ante estas demandas, es necesario un posicionamiento ético que acompañe y resguarde al sujeto y a su tiempo subjetivo, teniendo en cuenta, que uno de los efectos del discurso de la ciencia puede ser la forclusión del sujeto.

De pronto, la hipervirtualidad nos hace estar exageradamente más ocupados que antes de la pandemia. En muchos sujetos, aparece como síntoma una especie de hiperactividad generalizada, que va totalmente a contracorriente de lo que una pandemia implica. La pandemia nos detiene, nos confronta con la finitud que nos constituye como seres hablantes y mortales. Frenar, parar, esperar, detenerse a pensar. Esto es algo con lo que muchos sujetos no quieren saber nada, porque de otro modo emerge la angustia como respuesta. Sujetos que en sus alocados ritmos de vida creen evadir el hecho de que somos mortales. La implicación de la pandemia en este punto es insoslayable.

La hipervirtualidad, ofrece como objeto de mercado dos ilusiones: la ilusión de la cercanía, del no alejamiento (Heidegger, 1927) y la ilusión de presencia continua, inducida por las pantallas interconectadas. Según Butler (2017) es un fármaco mal diseñado que apenas disimula el efecto adverso producido sobre el lazo social, aquel de los intersticios 
entre los cuerpos cotidianos. El Neoliberalismo conlleva el peligro de generar una clínica masificadora que, siguiendo el imperativo de inmediatez de nuestro tiempo, no solo no se detiene en el deseo del sujeto sino que lo forcluye. Los portavoces de la ciencia posmoderna creen que para cada deseo hay un objeto y para cada desilusión un psicofármaco. El sujeto pasa así a ser un cuerpo en busca de pharmakos.

En ocasiones, el uso de las redes sociales puede funcionar como un pharmakos para el sujeto. Si bien su uso data de hace más de quince años, a partir del quédate en casa venimos escuchando sobre todo en la labor clínica, que se empezó a estilar en algunos sujetos, el compartir su vida casi en vivo, sin filtro se dice ahora, como un Gran Hermano que el sujeto mismo se impone.

En este punto, nos surgen algunos interrogantes. ¿Qué sucede con la intimidad al usar las redes sociales de forma exacerbada? ¿No será que la intimidad termina siendo lo contrario? Notamos en los relatos de la clínica que muchas veces la intimidad se torna pública con una perentoriedad eximida de pudor. Del mismo modo, nos encontramos, como efecto de la hipervirtualidad, con que el cuerpo del otro es intangible. La textura de su piel, la intención de su mirada, todo esto se pierde en el mar de lo virtual.

Ahora bien, es importante señalar que, muchas veces, algunos sujetos, sobre todo aquellos que ven como un padecimiento el no estar en pareja o vivir solos, se vuelcan hacia las redes sociales quizás como un modo de no sentirse tan solos, y a veces, se termina generando un efecto no deseado. Cada vez más, nos encontramos en la clínica con relatos en donde el sujeto utiliza las redes sociales bajo la lógica amo/esclavo. Esto resulta sumamente contraproducente, en ocasiones para quienes buscan acallar la pena de la soledad, porque genera un goce sin lazo que se origina en el fenómeno de la soledad y que al mismo tiempo, la acentúa.

Pareciera que se produce una erotización de la pantalla en sintonía con el individualismo posmoderno. Individuos aislados que a través de aparatos electrónicos, conforman una red de conexiones. Según el filósofo coreano B. Han (2014), se trata de un enjambre digital y está constituido precisamente por individuos aislados. Este homo digitalis es el sujeto neoliberal; lo que caracteriza la actual constitución social es la soledad, la atomización, al reducirse los espacios de acción común y de lazo social, según Han.

\section{CONCLUSIONES}

Algunas reflexiones finales: Nuevos desafíos a la clínica psicoanalítica: 
A lo largo del presente trabajo, nos hemos permitido transitar por la pregunta acerca de algunas de las diferentes maneras de atravesamiento subjetivo de la situación de pandemia, y del estado de confinamiento. Hemos intentando recorrer nuestro escrito, delimitando nuestra praxis como horizonte y punto de partida de la reflexión.

El confinamiento modificó nuestras vidas y la vida de nuestros analizantes. A partir de dicha medida epidemiológica, la virtualidad cobró una sobrestimación en la vida de los sujetos, al punto tal que muchos sujetos se encontraron angustiados, sumergidos en el océano de lo virtual. En este sentido, tomando como máxima la cita de Lacan (1953/1979): "Mejor pues que renuncie quien no pueda unir a su horizonte, la subjetividad de su época”. (p. 138), nos propusimos investigar cómo sostener esta máxima, tomando como referencia la pandemia como el horizonte de la subjetividad de nuestra época.

El psicoanálisis desde hace mucho tiempo ha ofrecido y sostenido el derecho de un sujeto a un goce que no sea perpetuo, entendido éste como lo que no puede definirse por su utilidad social, y preservar su deseo; en esto consiste, en gran parte, la ética en la clínica psicoanalítica.

Con el confinamiento surge la angustia, los temores, la desesperación, la soledad como un fantasma, la incertidumbre; distintos modos de atravesamiento singular de una situación tan impredecible como traumática como lo es el contexto de pandemia. Aquí relanzamos la apuesta a clínica, a nuestra clínica, ya que más que nunca, los sujetos necesitan contar con una práctica de escucha estrictamente ética y que pueda hacer frente a los desafíos que implica este complejo momento.

Lo que hemos denominado como hipervirtualidad, esas estructuras novedosas y en constante cambio que hemos analizado, como ser, distintas figuras de la vida on-line, el uso de redes sociales, el análisis on-line; resultan un desafío tanto para el psicoanálisis como para los psicoanalistas. Entendemos que no se trata de demonizar el uso de lo virtual y sus derivados, sino de suscitar conversaciones, con otras disciplinas sobre el tema, aportando no un estándar prefabricado, sino la propuesta siempre renovada de privilegiar la singularidad del sujeto.

Sabemos que la única opción que tenemos es incluirnos con nuestra particularidad, en el mercado de saberes, como un saber que no es como los demás. La práctica clínica en que estamos inmersos, es el campo de una praxis que apunta al meollo de lo real, diferenciándose de este modo, de otras prácticas que apuntan a la "coherencia" y a librar prontamente al sujeto de sus conflictos; ya que nos preocupamos por lo que no anda, no 
para corregirlo, como impone la posición del amo: que las cosas anden bien, sino precisamente para que eso que un sujeto atraviesa, pueda empezar a hablar.

\section{REFERENCIAS BIBLIOGRÁFICAS:}

Butler, J. (2017). Cuerpos aliados y lucha política. Buenos Aires, Argentina, Planeta.

Byung-Chul, H. (2014). En el enjambre. Barcelona, España, Herder, pág. 26.

Heidegger, M. (1927). El ser y el tiempo. México: Fondo de Cultura Económica.

Lacan, J. (1953/1979) Escritos 1. México. Edit. Siglo XXI. 1979.

Lacan. J. (2005). Seminario 7 La ética del Psicoanálisis. Buenos Aires, Argentina, Paidós.

Lacan, J. (2005). Seminario 10 La angustia. Buenos Aires, Argentina, Paidós.

Lacan, J. (1969-70/1992). Seminario 17 El reverso del psicoanálisis. Buenos Aires, Argentina, Paidós.

OMS (2020) Organización Mundial de la Salud. Recuperado de https://www.who.int/es/emergencies/diseases/novel-coronavirus2019?gclid=EAlalQobChMlx6vthp2K6gIVihCRCh2eXA8kEAAYASAAEgKsovD B WE 